\title{
ADIÇÃO DE CARBONO E NITROGÊNIO E SUA RELAÇÃO COM OS ESTOQUES NO SOLO E COM O RENDIMENTO DO MILHO EM SISTEMAS DE MANEJ $\mathbf{O}^{(1)}$
}

\author{
T. LOVATO(2), J . MIELNICZUK ${ }^{(3)}$, C. BAYER ${ }^{(3)} \&$ F. VEZZANI (4)
}

\begin{abstract}
RESUMO
Experimentos de longa duração constituem ferramenta valiosa para o estudo da dinâmica da matéria orgânica no solo. Com esse objetivo, realizou-se a presente pesquisa a qual foi baseada em experimento instalado, em 1985, em um Argissolo Vermelho degradado pelo cultivo inadequado por 16 anos. 0 experimento está localizado na Estação Experimental Agronômica da UFRGS, em E Idorado do Sul (RS), e consiste em três sistemas de preparo de solo (preparo convencional-PC, preparo reduzido-PR, e plantio direto-PD) em parcelas principais, três sistemas de culturas (aveia/milho-A/M, ervilhaca/milho-E/M, e aveia + ervilhaca/ milho + caupi-A +E/M + C), em subparcelas, e duas doses de $\mathbf{N}$ mineral na cultura do milho (0 e $\left.139 \mathrm{~kg} \mathrm{ha}^{-1}\right)$, em subblocos, distri buídos segundo um delineamento de blocos ao acaso, com três repetições. As adições de $\mathbf{C}$ e $\mathbf{N}$ pelas culturas foram estimadas para o período experimental de 13 anos; o solo foi amostrado, em setembro de 1998, em seis camadas, até à profundidade de 0,30 m, analisado em relação aos teores de carbono orgânico total (COT) e nitrogênio total (NT), tendo sido calculados os estoques desses elementos nas camadas de 0-0,175 e 0,175-0,30 m. As leguminosas contribuíram para a maior adição anual de $\mathrm{C}$ e $\mathrm{N}$ ao solo pelos sistemas de culturas, que variaram de 4,17 a $8,39 \mathrm{Mg} \mathrm{ha}^{-1}$ e de -21 a $178 \mathrm{~kg} \mathrm{ha}^{-1}$, respectivamente. As maiores adições de C e N refletiram-se num maior acúmulo de COT e NT na camada de 0-0,175 m do solo em PD e em gradativa elevação do rendimento do milho nos três sistemas de preparo. A adição anual de C (A) necessária para manter o estoque inicial de

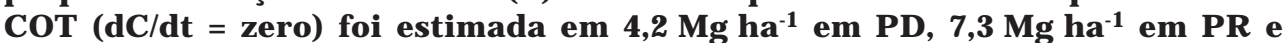
$8,9 \mathrm{Mg} \mathrm{ha}^{-1}$ em PC. De forma similar, a adição anual de $\mathrm{N}$ necessária para manter
\end{abstract}

\footnotetext{
(1) Recebi do para publicação em novembro de 2002 e aprovado em outubro de 2003.

(2) Professor do Departamento de Solos da Universidade Federal de Santa Maria - UFSM. CEP 97105-900 Santa Maria (RS). Email: thlovato@creta.ccr.ufsm.br

(3) Professor do Departamento de Solos da Universidade Federal do Rio Grande do Sul - UFRGS. CEP 90001-970 Porto Alegre (RS). Bolsista do CNPq. E-mail: mieln@vortex.ufrgs.br; cimelio.bayer@ufrgs.br

(4) Pós-Doutorando do Departamento de Solos, UFSM. Bolsista Recém-Doutor do CNPq. E-mail: fvezzani@terra.com.br
} 
os estoques iniciais (dN/dt = zero) foi estimada em $5 \mathrm{~kg} \mathrm{ha}^{-1}$ para o PD, $31 \mathrm{~kg} \mathrm{ha}^{-1}$ para o PR e $94 \mathrm{~kg} \mathrm{ha}^{-1}$ para o PC. Estimou-se, pelo coeficiente angular da regressão linear que relaciona as taxas anuais de adição de $C$ (A) e a variação anual nos estoques de COT na camada de $0-0,175 \mathrm{~m}$ do solo (dC/dt), que 12,9, 8,1 e $11,5 \%$ do $C$ adicionado ao solo foi retido na matéria orgânica do solo em PD, PR e PC, respectivamente, o que corresponde a uma estimativa aproximada do coeficiente de humificação $\left(k_{1}\right)$. Analogamente, estimou-se que 49,7, 21,0 e 33,1 \% da quantidade líquida de $\mathbf{N}$ adicionada foi retida como NT no solo em PD, PR e PC, respectivamente. A taxa de perda de COT do solo $\left(k_{2}\right)$, calculada para a

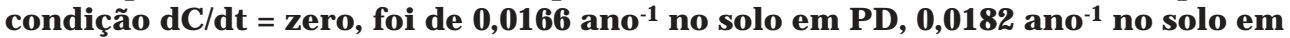
PR, e 0,0314 ano-1 no solo em PC. O plantio direto, pela diminuição da taxa de perda de matéria orgânica $\left(k_{2}\right)$, e os sistemas de culturas com leguminosas, pela alta adição de $\mathbf{C}$ fotossintetizado e de $\mathbf{N}$ fixado simbioticamente, são boas alternativas para recuperar os estoques de COT e NT do solo e aumentar o rendimento do milho na região subtropical do Sul do Brasil.

Termos de indexação: leguminosas, matéria orgânica, plantio direto, preparo reduzido, preparo convencional, solos subtropicais.

\section{SUMMARY: CARBON AND NITROGEN ADDITION RELATED TO STOCKS OF THESE ELEMENTS IN SOIL AND CORN YIELD UNDER MANAGEMENT SYSTEMS}

Long-term experiments are essential for research about organic matter dynamics of soils. This paper reports results of an experiment install ed in September 1985 on a Pal eudult soil degraded under inadequate management for 16 years. The experiment was conducted at the Experimental Station of the Federal University of Rio Grande do Sul (Brazil) in Eldorado do Sul county. Thresoil tillagemethods (conventional tillage CT, reduced tillage RT and no-tillage-NT), threecrop systems (oat/ corn-O/ C, vetch/ corn-V/ C and oat + vetch/ corn + cowpea-O $+\mathrm{V} / \mathrm{C}+\mathrm{Cp}$ ), and two $\mathrm{N}$ rates applied to corn as urea ( 0 and $139 \mathrm{~kg} \mathrm{ha}^{-1}$ ) weretested. A split-plot design arranged in randomized blocks with threereplications was used with soil tillage as main pl ot, the cropping systems as sub-plots and nitrogen rates as sub-blocks. Carbon and nitrogen addition by crops was estimated for the experimental period of 13 years. In September 1998, the soil was sampled in six layers down to $0.30 \mathrm{~m}$ depth, and total organic carbon (TOC) and total nitrogen (TN) contents weredetermined in each layer and then calculated for the 0-0.175 $\mathrm{m}$ and 0.175-0.30 m layers. Legumes were responsiblefor thegreatest annual soil $\mathrm{C}$ and $\mathrm{N}$ increase by crops $\left(4.17\right.$ to $8.39 \mathrm{Mg} \mathrm{ha}^{-1}$ and -21 to $178 \mathrm{~kg} \mathrm{ha}^{-1}$, respectively). The highest $\mathrm{C}$ and $\mathrm{N}$ additions were positively related to these elements stocks in the soil under NT (0-0.175 m layer), and promoted gradual corn yield increase in all soil tillage treatments. The annual rate of $C$ addition $(A)$ necessary to maintain de initial condition $(\mathrm{dC} / \mathrm{dt}=z e r o)$ was estimated at $4.2 \mathrm{Mg} \mathrm{ha}^{-1}$ for $\mathrm{NT}, 7.3 \mathrm{Mg} \mathrm{ha}^{-1}$ for RT and $8.9 \mathrm{Mg} \mathrm{ha}^{-1}$ for CT. Similarly, the annual rate of $\mathrm{N}$ addition required to maintain the initial condition (dN/ dt =zero) was $5 \mathrm{~kg} \mathrm{ha}^{-1}$ for $\mathrm{NT}, 31 \mathrm{~kg} \mathrm{ha}^{-1}$ for RT, and $94 \mathrm{~kg} \mathrm{ha}^{-1}$ for CT. An estimation by theangular coefficient of thelinear regression, which relates the annual $\mathrm{C}$ addition rates and annual TOC stock variation in the surface layer, cal culated that $12.9 \%$ for NT, $8.1 \%$ for RT, and $11.5 \%$ for CT of the C added to the soil was retained in the soil organic matter, representing approxi matel y the humification coefficient $\left(\mathrm{k}_{1}\right)$. Likewise, it was estimated that $49.7 \%$ of thenet annual $\mathrm{N}$ addition under NT, $21.0 \%$ under RT, and $33.1 \%$ under CT was retained as TN in the soil. The TOC loss coefficient from the soil $\left(\mathrm{k}_{2}\right)$, calculated for the condition $\mathrm{dC} / \mathrm{dt}=$ zero, was $0.0166 \mathrm{yr}^{-1}$ under NT, $0.0182 \mathrm{yr}^{-1}$ under RT, and $0.0314 \mathrm{yr}^{-1}$ under CT. No-tillage systems with the reduction of TOC loss $\left(\mathrm{k}_{2}\right)$, and legume based crop systems with the high $\mathrm{C}$ and $\mathrm{N}$ additions are good al ternatives to recover the soil TOC and TN stocks and increase corn yield in the subtropical region of southern Brazil.

Index terms: legume crops, soil organic matter, no-tillage, reduced tillage, conventional tillage, subtropical soils. 


\section{INTRODUÇÃO}

O solo é um sistema aberto, com permanente troca de matéria e energia com o meio (Addiscott, 1995), e complexo, em virtude de uma intrincada rede de relações entre os subsistemas que o compõem, representados pel os vegetais, organismos (macro e microrganismos) e matéria mineral. Os vegetais são os principais responsáveis pela adição ao solo de compostos orgânicos primários sintetizados no processo de fotossíntese, utilizando energia solar, $\mathrm{CO}_{2}$ do ar, água e nutrientes do solo. Os organismos, com destaque aos microrganismos heterotróficos, obtêm energia para o seu desenvolvimento pela decomposição de resíduos vegetais e da matéria orgânica do solo, liberando $\mathrm{CO}_{2}$ para atmosfera, nutrientes, e uma gama de compostos orgânicos secundários oriundos do metabolismo mi crobiano, os quais passam a compor a matéria orgânica do solo (Vezzani, 2001).

A matéria orgânica interage com minerais no solo formando complexos organominerais por meio de diversos mecanismos de interação, resultando em partículas secundárias de diversos tamanhos e formas, desde microagregados $(<250 \mu \mathrm{m})$ até macroagregados de al guns milímetros de tamanho (Tisdall \& Oades, 1982). As plantas, pela ação do seu sistema radicular (Silva \& Mielniczuk, 1997), e as hifas de fungos (Miller \& J astrow, 1990) potencializam estas interações na formação de agregados estáveis, principalmente pela aproximação de partículas, exsudações bem distribuídas na matriz do solo e união física de agregados de diferentes tamanhos. As interações com os minerais e a formação de agregados diminuem a ação dos mi crorganismos decompositores, contribuindo para o acúmulo de compostos orgânicos no solo. O processo de proteção física da matéria orgânica é mais intenso em solos não revolvidos (Feller \& Beare, 1997; Six et al., 1999).

Dependendo da magnitude do fluxo de carbono propiciado pelo subsistema vegetal, haverá maior ou menor atividade biológica, produção decompostos orgânicos secundários, agregação do solo e aparecimento de outras propriedades emergentes do sistema solo. De modo geral, as propriedades emergentes do ciclo do $C$ no solo (teor de matéria orgânica, agregação, porosidade, infiltração deágua, retenção de água, aeração, CTC, balanço de N, dentre outras) melhoram a qualidade do solo (van Breemer, 1993; Vezzani, 2001).

Os estoques de matéria orgânica do solo são determinados pela razão entre as quantidades de carbono $C$ adicionadas $\left(k_{1} A\right)$ e perdidas $\left(k_{2} C\right)$, sendo sua variação temporal (dC/dt) expressa pela equação $\mathrm{dC} / \mathrm{dt}=-\mathrm{k}_{2} \mathrm{C}+\mathrm{Ak_{1 }}$. Nesta equação, A representa o $C$ fotossintetizado adicionado anual mente ao sol o na forma de resíduos vegetais, exsudatos radiculares e raízes ( $\mathrm{Mg} \mathrm{ha}^{-1} \mathrm{ano}^{-1}$ ) e C representa o estoque de carbono orgânico total (COT) no solo ( $\left.\mathrm{Mg} \mathrm{ha}^{-1}\right)$. Os coeficientes $k_{1}$ e $k_{2}$ representam, em base anual, respectivamente, a fração do $C$ adicionado (A), efetivamente retido no solo na forma de matéria orgânica, e a fração do COT do solo, que é perdido por decomposição microbiana, erosão e lixiviação (Dalal \& Mayer, 1986).

O uso do solo para fins agrícolas interfere na adição de $C(A)$ pela sel eção de sistemas de culturas com capaci dades variadas de adi ção de fitomassa ao I ongo do ano. Normalmente, sistemas com pousios, culturas de baixa produtividade, quei ma ou remoção de resíduos culturais apresentam baixo val or anual de A. Em situação oposta, encontram-se os sistemas intensivos, com presença de culturas altamente produtivas durante todo ano e retorno dos resíduos ao solo. O coeficiente $k_{1}$ normalmente é pouco afetado pelas práticas de manejo. No entanto, a forma de adição do $\mathrm{C}$ ao sol o pode ter influência nos val ores de $k_{1}$, sendo os maiores valores observados para o C adicionado pelo sistema radicular (Balesdent \& Balabane, 1992, 1996; Bolinder et al., 1999). Neste contexto, culturas com sistema radicular abundante e agressivo, como gramíneas forrageiras perenes, que alocam uma maior fração do $C$ fotossintetizado para as raízes do que culturas anuais (Shamoot et al., 1968), serão mais eficientes em aumentar os estoques de COT do solo.

A taxa de perda da matéria orgânica $\left(k_{2}\right)$ é bastante influenciada pelo revolvimento do solo, o qual estimula a ação dos microrganismos decompositores. Em um mesmo solo, orevolvimento pode duplicar o val or de $k_{2}$ em relação a um sistema de manejo sem revolvimento (Bayer et al., 2000c), sendo esse efeito menos pronunciado em solos de textura argilosa e com mineralogia oxídica (Bayer, 1996). Em síntese, um sistema de manejo que objetiva recuperar estoques de COT do solo deve maximizar as entradas $\left(\mathrm{k}_{1} \mathrm{~A}\right)$ e minimizar as perdas $\left(\mathrm{k}_{2} \mathrm{C}\right)$ anuais de $\mathrm{C}$ no solo.

Sendo ambos componentes da matéria orgânica, a dinâmica do $\mathrm{N}$ no solo é intimamente associada à dinâmica do $C$, apenas alterando os mecanismos de adição e de perda dos el ementos no sistema (Bayer et al., 2000a,b). Além disso, sol os degradados pelo cultivo e com baixos teores de COT normalmente são deficientes em N, o que limita a adição de C, principalmente, em sistemas constituídos por gramíneas. A inclusão deleguminosas nas rotações e a adubação nitrogenada constituem práticas altamente eficientes para o incremento dos estoques de COT e NT, melhoria da qualidade do solo e da produtividade das culturas (Teixeira et al., 1994; Testa et al., 1992; Vezzani, 2001).

O presente estudo foi realizado em experimento de longa duração (13 anos) eteve por objetivo avaliar o efeito de sistemas de manejo de solo, constituídos por sistemas deculturas, preparos de solo eadubação nitrogenada, nos estoques de COT e NT de um 
Argissol o Vermel ho degradado e na produtividade do milho. A fração do C adicionado retido na matéria orgânica do solo $\left(\mathrm{k}_{1}\right)$ e a taxa de perda da matéria orgânica $\left(k_{2}\right)$ foram estimadas, em bases anuais, a partir da interpretação dos resultados experimentais.

\section{MATERIAL E MÉTODOS}

\section{Descrição do local}

O estudo foi baseado em um experimento conduzido, desde 1985, na Estação Experimental Agronômica da UFRGS (30 두 ' 52 " Sul e 51 ㅇ' ' 08 " Oeste), em E Idorado do Sul (RS). O clima local é subtropical úmido, Cfa, pela classificação de Köeppen. A temperatura média anual é de $19,4{ }^{\circ} \mathrm{C}$, variando as médias normais mensais de 13,9 a $24,9{ }^{\circ} \mathrm{C}$. A preci pitação média anual é de $1.440 \mathrm{~mm}$, com variação mensal entre 95,7 mm e $168 \mathrm{~mm}$, com curtos períodos de déficit hídrico no verão (Bergamaschi \& Guadagnin, 1990). A área experimental apresenta declividade variando de 2 a $6 \%$ e altitude de $46 \mathrm{~m}$.

O experimento situa-se em solo classificado como Argissolo Vermelho típico (EMBRAPA, 1999) e Paleudult (Soil Survey Staff, 1998). A textura na camada de 0-0,2 m é franco-argilo-arenosa, com $540 \mathrm{~g} \mathrm{~kg}^{-1}$ de areia, $220 \mathrm{~g} \mathrm{~kg}^{-1}$ de silte e $240 \mathrm{~g} \mathrm{~kg}^{-1}$ de argila. Na fração argila, predominam caulinita $\left(720 \mathrm{~g} \mathrm{~kg}^{-1}\right)$ e óxidos de ferro (109 $\left.\mathrm{g} \mathrm{kg}^{-1} \mathrm{Fe}-\mathrm{DCB}\right)$. O sol o em campo nativo, adjacente ao experimento, contém estoques de COT e de NT de $44,76 \mathrm{Mg} \mathrm{ha}^{-1} \mathrm{e}$ $3.620 \mathrm{~kg} \mathrm{ha}^{-1}$, na camada de 0-0,175 m, e de $67,22 \mathrm{Mg} \mathrm{ha}^{-1}$ e $5.320 \mathrm{~kg} \mathrm{ha}^{-1}$, na camada de 0-0,30 m, respectivamente. Por sua vez, quando da instalação do experimento, em 1985, o solo apresentava estoques de COT e NT de, respectivamente, $32,55 \mathrm{Mg} \mathrm{ha}^{-1}$ e2.710 $\mathrm{kg} \mathrm{ha}^{-1}$, na camada de0-0,175 m, e de $51,61 \mathrm{Mg} \mathrm{ha}^{-1}$ e $4.340 \mathrm{~kg} \mathrm{ha}^{-1}$, na camada de 0-0,30 m, reduzidos para estes valores pelo cultivo do solo por 16 anos (1969-1984) baseado em práticas de intenso revolvimento e baixa adição de resíduos vegetais (Lovato, 2001).

\section{Tratamentos e delineamento experimental}

O experimento seguiu um delineamento experimental de blocos casualizados, com parcelas subdivididas, com três repetições. As parcelas principais $(15 \times 20 \mathrm{~m})$ consistiram de três sistemas de preparo de solo (preparo convencional-PC, preparo reduzido-PR e plantio direto-PD), e as subparcelas $(5 \times 20 \mathrm{~m})$ de três sistemas de culturas [aveia preta (Avena strigosa)/milho (Zea mays)-A/M, ervilhaca (Vicia sativa)/milho-E/M e aveia + ervilhaca/milho + caupi (Vigna unguiculata)-A + $\mathrm{E} / \mathrm{M}+\mathrm{C}$ ]. Duas doses de $\mathrm{N}$ mineral $\left(0 \mathrm{~kg} \mathrm{ha}^{-1}\right.$ - NO e $180 \mathrm{~kg} \mathrm{ha}^{-1}$ - N180), na forma de uréia, foram aplicadas na cultura do milho em faixas nos blocos (subblocos com $45 \times 10 \mathrm{~m}$ ).
Os preparos de solo foram realizados na primavera-verão, antes da semeadura do milho; no outono, as culturas de cobertura do solo foram implantadas em plantio direto em todo o experimento. O PC consistiu de uma aração e duas gradagens; o PR consistiu de uma escarificação seguida de uma gradagem leve, eo PD na semeadura do milho na camada de resíduos vegetais na superfície do solo. Nos três sistemas de preparo de solo, os resíduos das culturas de cobertura edo milho foram manejados com uma passagem de rolo-faca. Durante o experimento, houve variações nos consórcios da culturas de outono-inverno e nas quantidades de $\mathrm{N}$ mineral aplicadas. Nos atuais tratamentos $A+E / M+C$ e $E / M$, utilizou-se, no período de 1985-1989, o trevo subterrâneo (Trifol ium subterraneum) em lugar da ervilhaca. No sistema E/M, utilizou-se, entre 1985 e 1989, o consórcio aveia+trevo, e entre 1990 e 1994, o consórcio aveia + ervilhaca. Em relação ao $\mathrm{N}$ mineral, a partir de 1994, a dose de $180 \mathrm{~kg} \mathrm{ha}^{-1}$ foi usada em substituição à dose de $120 \mathrm{~kg} \mathrm{ha}^{-1}$, resultando em uma média anual nos 13 anos de $139 \mathrm{~kg} \mathrm{ha}^{-1}$ (N 139).

As práticas do experimento, relativas aos preparos de solo, adubação, calagem, semeadura, irrigação e controle de invasoras, encontram-se descritas em Freitas et al. (1996), Bayer \& Mielniczuk (1997a,b), Bayer et al. (2000a,b), Amado et al. (2000) e Lovato (2001).

\section{Amostragem e análise do solo}

Em setembro de 1998, após a rolagem das culturas de inverno e precedendo a semeadura do milho, foram coletadas amostras de solo nas profundidades de $0-0,025,0,025-0,05,0,05-0,075$, $0,075-0,125,0,125-0,175$ e $0,175-0,30$ m em todos os tratamentos. A amostragem do sol o foi manual, em uma faixa de 0,20-0,50 m, transversal às linhas de semeadura do milho. As amostras de solo foram secas ao ar emoídas até passar em peneira de $2 \mathrm{~mm}$. Das amostras assim preparadas, retirou-se uma subamostra a qual foi submetida à moagem em gral de porcelana até passar em peneira de $0,5 \mathrm{~mm}$ para posterior análise dos teores de COT e de NT pelos métodos Walkley-Black eK jeldhal, respectivamente (Tedesco et al., 1995). Os estoques de COT e NT do solo foram calculados com base nos valores de densidades de solo apresentados em Bayer (1996).

\section{Esti mativas das adições de $\mathbf{C}$ e $\mathbf{N}$ ao solo pelos sistemas de culturas}

As adições anuais de $C$ e de $N(A)$ pelos sistemas deculturas foram estimadas a partir dos resultados de rendimento de grãos do milho, matéria seca produzida e $\mathrm{N}$ absorvido pel o milho e pelas culturas de cobertura de solo, bem como as quantidades de $\mathrm{N}$ exportado pela colheita dos grãos do milho, resumidos em Lovato (2001). Considerou-se a contribuição média do sistema radicular em 30 \% 
do total de $\mathrm{C}$ e $\mathrm{N}$ contidos na parte aérea. Para calcular as adições de $\mathrm{C}$ pelas culturas de cobertura e pel o milho, utilizou-se o teor médio de $40 \%$ deste elemento na matéria seca (Lovato, 2001).

\section{Estimativas do coeficiente de humificação $\left(k_{1}\right)$ e da taxa de perda de matéria orgânica $\left(k_{2}\right)$}

A fração do $C$ adicionado retido na matéria orgânica do solo $\left(\mathrm{k}_{1}\right)$, denominado coeficiente de humificação, foi estimada, de forma aproximada, a partir do coeficienteangular da regressão linear que relaciona as quantidades de $\mathrm{C}$ adicionadas anualmente com a taxa de variação anual (dC/dt) no estoque de COT na camada de 0-0,175 m do solo. Analogamente, estimou-se a fração da quantidade líquida de $\mathrm{N}$ adicionada que foi retida como NT no solo.

A partir dos valores de adição efetiva de $C$ ao solo pel os sistemas de culturas $\left(\mathrm{k}_{1} \mathrm{~A}\right)$ e dos estoques de COT na camada de 0-0,175 m do solo, estimou-se a taxa anual de perda de matéria orgânica do solo $\left(\mathrm{k}_{2}\right)$ em cada sistema de preparo de solo, utilizandose a equação $d C / d t=k_{1} A-k_{2} C$, na condição de $\mathrm{dC} / \mathrm{dt}=$ zero (Dalal \& Mayer, 1986). Nesta condição, $\mathrm{k}_{1} \mathrm{~A}=\mathrm{k}_{2} \mathrm{C}$ e $\mathrm{k}_{2}=\mathrm{k}_{1} \mathrm{~A} / \mathrm{C}$, em que $\mathrm{C}$ representa $\mathrm{O}$ estoque de COT do solo na condição inicial $\left(32,55 \mathrm{Mg} \mathrm{ha}^{-1}\right)$ eA representa a taxa de adição anual de $C$ necessária para manter o estoque inicial de COT do solo inal terado ao longo do tempo, ou seja, $\mathrm{dC} / \mathrm{dt}=$ zero.

\section{Análise estatística}

O efeito dos sistemas de preparo de solo, sistemas deculturas e da adubação nitrogenada nos estoques de COT e de NT do solo tiveram sua significância avaliada pela análiseda variância. A diferença entre médias detratamentos foi obtida pel oteste de Tukey a $5 \%$. A relação entre variáveis foi determinada pela significância dos coeficientes de regressões polinomiais a 1 e $5 \%$.

\section{RESULTADOS E DISCUSSÃO}

\section{Adições de $\mathbf{C}$ e $\mathbf{N}$ pelos sistemas de culturas e rendimento do milho}

Na figura 1a, está apresentada a adição média anual de $\mathrm{C}$ ao solo pel os sistemas de culturas (parte aérea e raízes). Verifica-se que a adição variou, na média dos preparos de solo, entre 4,11 $\mathrm{Mg} \mathrm{ha}^{-1} \mathrm{ano}^{-1}$, no sistema A/M sem $\mathrm{N}$ mineral, e 8,14 $\mathrm{Mg} \mathrm{ha}^{-1}$ ano $^{-1}$, no sistema $A+E / M+C$ com adição anual de $139 \mathrm{~kg} \mathrm{ha}^{-1}$ de N mineral. Comoregra geral, o milho apresentou a maior contribuição na adição de $C$ ao solo, destacando a sua importância em sistemas de culturas, quanto à adição de biomassa. A contribuição relativa das culturas de cobertura variou de 40 a $50 \%$, nos tratamentos sem $\mathrm{N}$ mineral, e de 30 a $40 \%$, nos tratamentos com adubação nitrogenada.

No entanto, além da adição de $C$ pelas leguminosas, estas espécies aumentaram a adição de C pelo milho, conforme pode ser verificado, comparando a contribuição do milho, sem adubação nitrogenada, nos sistemas $\mathrm{A}+\mathrm{E} / \mathrm{M}+\mathrm{C}$ eE/M, com a do sistema $A / M$. Os sistemas com leguminosas ( $E / M$ e $\mathrm{A}+\mathrm{E} / \mathrm{M}+\mathrm{C}$ ), sem $\mathrm{N}$ mineral, atingiram uma adição de C equivalente a $80-90 \%$ da verificada no mesmo sistema com adubação nitrogenada, superando, no caso do sistema $A+E / M+C$, a adição de $C$ verificada no sistema $\mathrm{A} / \mathrm{M}$ com $\mathrm{N}$ mineral. Esse efeito das leguminosas na adição de C está diretamente relacionado com o suprimento de $\mathrm{N}$ às culturas em sucessão (Amado et al., 2000; 2001), e não foi expressivo, quando realizada a adubação nitrogenada (Figura 1).
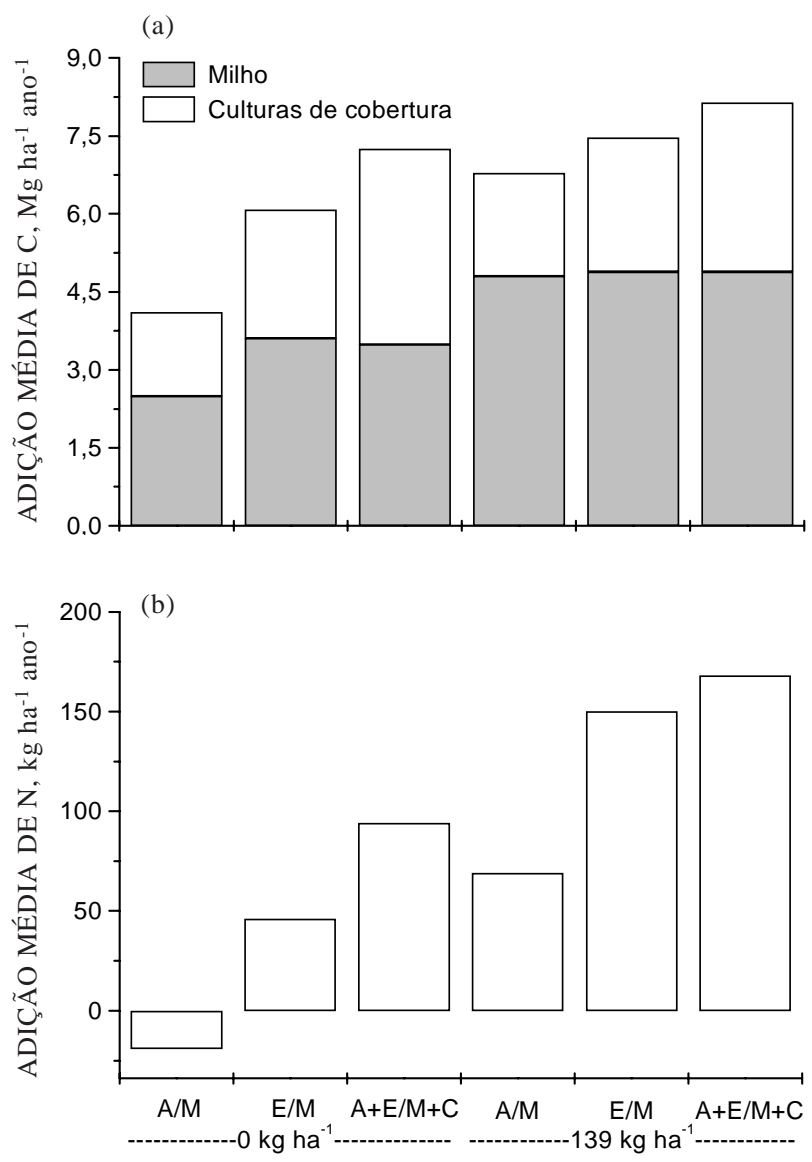

SISTEMA DE CULTURA E DOSE DE N

Figura 1. Quantidades anuais médias de C (a) e de N (b) adicionadas ao solo pelos sistemas de culturas, em duas doses de $\mathbf{N}$ mineral. Valores médios de três sistemas de preparo de solo no período de 1985 a 1998. $\mathrm{N}$ adicionado $=$ ( $\mathrm{N}$ adubo + $\mathbf{N}$ fixado simbioticamente)- $\mathrm{N}$ retirado na colheita. $\mathbf{A}=$ aveia, $\mathbf{M}=$ mi lho, $\mathbf{E}=$ ervilhaca, $\mathbf{C}=$ caupi. 
Quanto à avaliação das quantidades de N adicionadas ao solo pelos sistemas de culturas depara-se com dificuldades mai ores queas relativas às adições de $C$. E nquanto todo o $C$ adicionado pela fitomassa vem do ar via fotossíntese, o $\mathrm{N}$ na fitomassa vem do solo, da fixação simbiótica e da adubação nitrogenada. A dificuldade reside na separação do $\mathrm{N}$ reciclado, daquele efetivamente adicionadoao sistema. Esta separação normalmente é feita com o uso de técnicas de $\mathrm{N}$ marcado $\left(\mathrm{N}^{15}\right)$ (Ramos et al., 2001), ou com base em experimentos de campo (Teixeira et al., 1994; Amado et al., 2000).

Esta última técnica, utilizada na presente pesquisa, considera que o $\mathrm{N}$ absorvido pelas gramíneas (aveia e milho) provém exclusivamente do solo ou do adubo aplicado, e o $\mathrm{N}$ contido nas leguminosas, do solo e da fixação simbiótica. A contribuição da fixação simbiótica foi computada, descontando-se do $\mathrm{N}$ contido na fitomassa da leguminosa ou da mistura, o N absorvido pela aveia, acrescido do $\mathrm{N}$ do caupi, onde esta cultura estava presente. Esta forma de cálculo, cujos resultados encontram-se no quadro 1, provavelmente, superestima a contribuição da fixação simbiótica, principalmente na mistura de gramíneas e leguminosas. Neste quadro, a coluna VIII fornecea estimativa do $\mathrm{N}$ efetivamente adicionado ea col una IX a estimativa do $\mathrm{N}$ depositado sobre o solo pelas culturas, representando o $\mathrm{N}$ absorvido do solo (reciclagem) e o adicionado (fixado + adubo), subtraindo-se, em ambos os casos, oN retirado pel os grãos do milho. Para os cálculos efetuados veja o rodapé do quadro 1 . As adições pela chuva efixação assimbiótica não foram consideradas na presente pesquisa.

$\mathrm{Na}$ figura $1 \mathrm{~b}$, está representada a adição líquida de $\mathrm{N}$ ao solo, na média dos três preparos de solo, em que houve uma remoção média anual de aproximadamente $20 \mathrm{~kg}^{-1}$ no sistema $A / M$, decorrente da exportação pel os grãos de milho. Nos sistemas $\mathrm{E} / \mathrm{M}$ e $\mathrm{A}+\mathrm{E} / \mathrm{M}+\mathrm{C}$, houve adição líquida de $\mathrm{N}$ de aproximadamente 50 e $100 \mathrm{~kg} \mathrm{ha}^{-1} \mathrm{ano}^{-1}$, respectivamente. Com a aplicação de $\mathrm{N}$ mineral, a adição de $\mathrm{N}$ chegou próximo a $170 \mathrm{~kg} \mathrm{ha}^{-1} \mathrm{ano}^{-1}$. As quantidades de $\mathrm{N}$ depositadas sobre o solo pelos sistemas de culturas sem aplicação de $\mathrm{N}$ mineral variaram de $38 \mathrm{~kg} \mathrm{ha}^{-1} \mathrm{ano}^{-1}$, no sistema PR A/M, a $182 \mathrm{~kg} \mathrm{ha}^{-1} \mathrm{ano}^{-1}$, no PC $A+E / M+C$, enquanto,

Quadro 1. Quantidades médias anuais estimadas de nitrogênio adicionado, reciclado e retirado nos sistemas de culturas, com e sem adubação nitrogenada, em três sistemas de preparo de solo

\begin{tabular}{|c|c|c|c|c|c|c|c|c|c|c|}
\hline \multicolumn{2}{|c|}{ Sistema } & \multirow{3}{*}{$\begin{array}{c}\text { Aplicado } \\
\text { via adubo }\end{array}$} & \multicolumn{3}{|c|}{ Cultura de cobertura } & \multicolumn{2}{|c|}{ Milho } & \multirow[b]{2}{*}{$\begin{array}{c}\text { Total } \\
\text { reciclado(2) }\end{array}$} & \multirow[b]{2}{*}{$\begin{array}{c}\text { Total } \\
\text { adicionado(3) }^{(3)}\end{array}$} & \multirow{3}{*}{$\begin{array}{c}\text { Total } \\
\text { depositado } \\
\text { sobre o } \\
\text { solo(4) } \\
\text { IX }\end{array}$} \\
\hline Preparo & Cultura & & $\begin{array}{c}\text { Total } \\
\text { absorvido }\end{array}$ & $\begin{array}{l}\text { Absorvido } \\
\text { pela } \\
\text { Aveia }\end{array}$ & Fixado(1) & Absorvido & $\begin{array}{c}\text { Retirado } \\
\text { nos } \\
\text { grãos }\end{array}$ & & & \\
\hline & & & II & III & IV & $\mathbf{v}$ & VI & VII & VIII & \\
\hline & & & & & & $-\mathrm{kg} \mathrm{ha}^{-1}$ ano $^{-1}$ & de $\mathrm{N}$ & & & - \\
\hline PC & $\begin{array}{l}A / M \\
E / M \\
A+E / M+C\end{array}$ & $\begin{array}{l}0 \\
0 \\
0\end{array}$ & $\begin{array}{r}40 \\
133 \\
180\end{array}$ & $\begin{array}{l}40 \\
40 \\
40\end{array}$ & $\begin{array}{r}0 \\
93 \\
140\end{array}$ & $\begin{array}{l}23 \\
47 \\
40\end{array}$ & $\begin{array}{l}21 \\
44 \\
38\end{array}$ & $\begin{array}{l}63 \\
87 \\
80\end{array}$ & $\begin{array}{r}-21 \\
49 \\
102\end{array}$ & $\begin{array}{r}42 \\
136 \\
182\end{array}$ \\
\hline PR & $\begin{array}{l}A / M \\
E / M \\
A+E / M+C\end{array}$ & $\begin{array}{l}0 \\
0 \\
0\end{array}$ & $\begin{array}{r}36 \\
125 \\
170\end{array}$ & $\begin{array}{l}36 \\
36 \\
36\end{array}$ & $\begin{array}{r}0 \\
89 \\
134\end{array}$ & $\begin{array}{l}22 \\
40 \\
41\end{array}$ & $\begin{array}{l}20 \\
38 \\
38\end{array}$ & $\begin{array}{l}58 \\
76 \\
77\end{array}$ & $\begin{array}{r}-20 \\
51 \\
96\end{array}$ & $\begin{array}{r}38 \\
127 \\
173\end{array}$ \\
\hline PD & $\begin{array}{l}A / M \\
E / M \\
A+E / M+C\end{array}$ & $\begin{array}{l}0 \\
0 \\
0\end{array}$ & $\begin{array}{r}37 \\
114 \\
156\end{array}$ & $\begin{array}{l}37 \\
37 \\
37\end{array}$ & $\begin{array}{r}0 \\
77 \\
119\end{array}$ & $\begin{array}{l}18 \\
42 \\
38\end{array}$ & $\begin{array}{l}16 \\
39 \\
36\end{array}$ & $\begin{array}{l}55 \\
79 \\
75\end{array}$ & $\begin{array}{r}-16 \\
38 \\
83\end{array}$ & $\begin{array}{r}39 \\
117 \\
158\end{array}$ \\
\hline PC & $\begin{array}{l}A / M \\
E / M \\
A+E / M+C\end{array}$ & $\begin{array}{l}139 \\
139 \\
139\end{array}$ & $\begin{array}{r}42 \\
131 \\
150\end{array}$ & $\begin{array}{l}42 \\
42 \\
42\end{array}$ & $\begin{array}{r}0 \\
89 \\
108\end{array}$ & $\begin{array}{l}73 \\
73 \\
72\end{array}$ & $\begin{array}{l}70 \\
71 \\
69\end{array}$ & $\begin{array}{l}115 \\
115 \\
114\end{array}$ & $\begin{array}{r}69 \\
157 \\
178\end{array}$ & $\begin{array}{l}184 \\
272 \\
292\end{array}$ \\
\hline PR & $\begin{array}{l}A / M \\
E / M \\
A+E / M+C\end{array}$ & $\begin{array}{l}139 \\
139 \\
139\end{array}$ & $\begin{array}{r}46 \\
132 \\
141\end{array}$ & $\begin{array}{l}46 \\
46 \\
46\end{array}$ & $\begin{array}{r}0 \\
86 \\
95\end{array}$ & $\begin{array}{l}75 \\
71 \\
72\end{array}$ & $\begin{array}{l}72 \\
68 \\
69\end{array}$ & $\begin{array}{l}121 \\
117 \\
118\end{array}$ & $\begin{array}{r}67 \\
157 \\
165\end{array}$ & $\begin{array}{l}188 \\
274 \\
283\end{array}$ \\
\hline PD & $\begin{array}{l}A / M \\
E / M \\
A+E / M+C\end{array}$ & $\begin{array}{l}139 \\
139 \\
139\end{array}$ & $\begin{array}{r}42 \\
110 \\
134\end{array}$ & $\begin{array}{l}42 \\
42 \\
42\end{array}$ & $\begin{array}{r}0 \\
68 \\
92\end{array}$ & $\begin{array}{l}70 \\
72 \\
74\end{array}$ & $\begin{array}{l}67 \\
70 \\
71\end{array}$ & $\begin{array}{l}112 \\
114 \\
116\end{array}$ & $\begin{array}{r}72 \\
137 \\
160\end{array}$ & $\begin{array}{l}184 \\
251 \\
276\end{array}$ \\
\hline
\end{tabular}

$\mathrm{PC}=$ preparo convencional, $\mathrm{PR}=$ preparo reduzido e $\mathrm{PD}=$ plantio direto. $\mathrm{A}=$ aveia, $\mathrm{E}=$ ervilhaca, $\mathrm{M}=$ milho e $\mathrm{C}=$ caupi.

${ }^{(1)} \mathrm{N}$ fixado $=$ Colunas II $-\mathrm{III}$. ${ }^{(2)} \mathrm{N}$ total reciclado $=$ Colunas III $+\mathrm{V} .{ }^{(3)} \mathrm{N}$ total adicionado $=$ Colunas $(I+I \mathrm{~V})-\mathrm{VI} .{ }^{(4)} \mathrm{N}$ total depositado sobre o solo = Colunas $(\mathrm{I}+\mathrm{II}+\mathrm{V})-\mathrm{VI}$. 
quando foi aplicado $\mathrm{N}$ mineral, a variação foi de $184 \mathrm{~kg} \mathrm{ha}^{-1} \mathrm{ano}^{-1}$ no PC A/M a $292 \mathrm{~kg} \mathrm{ha}^{-1} \mathrm{ano}^{-1}$ no PC A +E/M + C (Quadro 1).

A maior quantidade líquida de $\mathrm{N}$ adicionado e a maior quantidade de $\mathrm{N}$ depositado sobre o solo influenciaram na adição de $C$ pel os resíduos vegetais (F igura 1a) e o rendimento de milho (Figura 2). No sistema $A / M$, sem $N$ mineral, no qual o balanço de $\mathrm{N}$ foi negativo, houve tendência de redução de rendimento de 1985/86 a 1997/98, enquanto, nos sistemas com leguminosas, nos quais o balanço de $\mathrm{N}$ foi positivo, houve aumento gradual de rendimento entreo início do experimento eo $13^{\circ}$ ano. Tendência similar foi observada no aumento do rendimento médio da cultura. Com aplicação de $\mathrm{N}$ mineral, verificou-se aumento expressivo de rendimento do milho entre 1985/86 e 1997/98, nos três sistemas de culturas, atingindo rendimentos superiores a $9 \mathrm{Mg} \mathrm{ha}^{-1}$ nesta última safra.

O aumento de rendimento ao longo dos anos deveseà melhoria das práticas de manejo, uso de híbridos mais produtivos, melhoria da qualidade do solo e, principalmente, ao aumento do suprimento de $\mathrm{N}$ mineral eaos sistemas de cul turas com leguminosas, que promoveram acúmulo deste nutriente no solo (Amado et al., 2001).

\section{Alteração nos estoques de carbono orgânico total (COT) do solo}

O cultivo dosolo, originalmente sob camponativo, no período que antecedeu a instalação do experimento (1969-1984), resultou na diminuição dos estoques de COT na camada de 0-0,175 m do solo de 44,76 para 32,55 $\mathrm{Mg} \mathrm{ha}^{-1}$, em razão do intenso revolvimento do solo com enxada rotativa e baixa

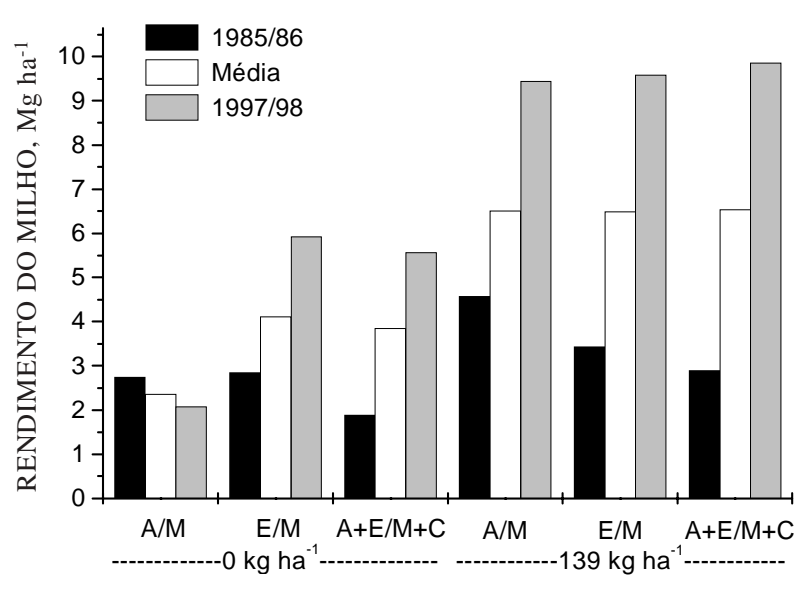

SISTEMA DE CULTURA E DOSE DE N

Figura 2. Rendimento de grãos de milho nos sistemas de culturas, em duas doses de $\mathbf{N}$ mineral. Médias de três sistemas de preparo de solo. $A=$ aveia, $M=$ milho, $E=$ ervilhaca, $C=$ caupi. adição de resíduos vegetais (Quadro 2). Durante o período experimental (1985-1998), os estoques de COT nesta camada do solo foram influenciados significativamente pel os preparos de solo, sistemas de culturas e doses de $\mathrm{N}$, não tendo sido observada interação entre as práticas de manejo (Quadro 2). $\mathrm{Na}$ camada de 0,175-0,30 m, o estoque de COT foi pouco alterado pelo cultivo do solo no período anterior à instalação do experimento e pelos tratamentos durante o experimento, onde apenas a aplicação de $\mathrm{N}$ mineral teve efeito significativo (Quadro 2).

O estoque de COT na camada de 0-0,175 m foi maior no solo em PD do que no solo em PR e PC, os quais não diferiram (Tukey $5 \%$ ), apesar da tendência do maior estoque de COT ocorrer no solo em PR. Os estoques de COT no solo $(0-0,175 \mathrm{~m})$ nos sistemas de culturas $E / M$ e $A+E / M+C$ não diferiram, porém promoveram maior acúmulo de COT no solo em comparação ao sistema A/M. A adubação nitrogenada aumentou o estoque de COT nas duas camadas de solo (0-0,175 e 0,175-0,30 m) (Quadro 2). Estes resultados são relacionados, conforme será discutido mais adiante, com as maiores taxas anuais de perda de matéria orgânica nos sistemas de preparo com revolvimento, bem como com a maior adição anual de $C$ pelos sistemas deculturas que têm suas deficiências de $\mathrm{N}$ supridas pela presença de leguminosas e adubação nitrogenada.

$\mathrm{Na}$ figura $3 \mathrm{a}$, são apresentados os estoques de COT na camada de $0-0,175 \mathrm{~m}$ do solo nos tratamentos A/M-PC e PD e A +E/M + C-PC e PD, com e sem aplicação de $\mathrm{N}$ mineral, bem como a sua comparação ao estoque original do solo em campo nativo (CNativo) e no início do experimento (1985). Verifica-se, nesta figura, a nítida recuperação dos estoques de COT pelo sistema PD A + E/M + C, mesmo sem aplicação de $N$, enfatizando a importância da presença de leguminosas nos sistemas agrícolas para a recuperação dos estoques de COT do solo. Este efeito foi ampliado pela utilização de $\mathrm{N}$ mineral. Observa-se, nesta figura, que, embora tenha ocorrido expressiva recuperação do estoque de COT do sol o no período experimental, ainda não foi atingido o estoque original do solo em campo nativo. Nota-se também o efeito del etério do revol vimento sobre o acúmul o de $C$ orgânico no solo, onde a alta adição de $C$ pelo sistema $A+E / M+C$ com $\mathrm{N}$ mineral não foi suficiente para manter os estoques de COT observados no início do experimento.

A localização do aporte de $C$ pelos resíduos vegetais resultou numa distribuição dos teores de COT no perfil do solo diferenciada entre os preparos de solo. Na figura 4a, é apresentado o efeito dos tratamentos extremos PC A/M e PD A + E/M + C com e sem $\mathrm{N}$ mineral sobre a distribuição do $\mathrm{C}$ orgânico no perfil do solo e sua relação com a 
Quadro 2. Carbono adicionado ao solo em base anual (média) e em 13 anos (total) e os estoques de carbono orgânico total (COT) nas camadas de 0-0,175 e 0,175-0,30 m de um Argissolo Vermelho sob campo nativo, por ocasião da implantação do experimento (1985) e após 13 anos (1998) sob três sistemas de preparo de solo, três sistemas de culturas e duas doses de $\mathbf{N}$ mineral

\begin{tabular}{|c|c|c|c|c|c|c|c|c|c|}
\hline \multirow{2}{*}{\multicolumn{2}{|c|}{ Sistema de manejo }} & \multicolumn{4}{|c|}{ C adicionado } & \multicolumn{4}{|c|}{ СОT (1998) } \\
\hline & & \multicolumn{2}{|c|}{ NO } & \multicolumn{2}{|c|}{ N139 } & \multicolumn{2}{|c|}{$0-0,175 \mathrm{~m}$} & \multicolumn{2}{|c|}{$0,175-0,30 \mathrm{~m}$} \\
\hline Preparo & Cultura & Média & Total & Média & Total & NO & N139 & NO & N139 \\
\hline & & \multicolumn{8}{|c|}{ - Mg ha-1 de C } \\
\hline PC & $\begin{array}{l}A / M \\
E / M \\
A+E / M+C\end{array}$ & $\begin{array}{l}4,23 \\
6,45 \\
7,52\end{array}$ & $\begin{array}{l}54,99 \\
83,85 \\
97,76\end{array}$ & $\begin{array}{l}6,67 \\
7,82 \\
8,39\end{array}$ & $\begin{array}{r}86,71 \\
101,66 \\
109,07\end{array}$ & $\begin{array}{l}25,87 \\
27,90 \\
30,26\end{array}$ & $\begin{array}{l}29,88 \\
31,58 \\
31,84\end{array}$ & $\begin{array}{l}19,11 \\
19,51 \\
19,37\end{array}$ & $\begin{array}{l}21,74 \\
20,79 \\
19,50\end{array}$ \\
\hline PR & $\begin{array}{l}A / M \\
E / M \\
A+E / M+C\end{array}$ & $\begin{array}{l}4,17 \\
5,98 \\
7,35\end{array}$ & $\begin{array}{l}54,21 \\
77,74 \\
95,55\end{array}$ & $\begin{array}{l}7,09 \\
7,47 \\
8,19\end{array}$ & $\begin{array}{r}92,17 \\
97,11 \\
106,47\end{array}$ & $\begin{array}{l}29,20 \\
32,08 \\
32,63\end{array}$ & $\begin{array}{l}30,16 \\
33,76 \\
33,88\end{array}$ & $\begin{array}{l}20,12 \\
20,19 \\
19,17\end{array}$ & $\begin{array}{l}20,65 \\
19,84 \\
20,79\end{array}$ \\
\hline PD & $\begin{array}{l}A / M \\
E / M \\
A+E / M+C\end{array}$ & $\begin{array}{l}3,92 \\
5,80 \\
6,90\end{array}$ & $\begin{array}{l}51,96 \\
75,40 \\
87,70\end{array}$ & $\begin{array}{l}6,63 \\
7,11 \\
7,83\end{array}$ & $\begin{array}{r}86,19 \\
92,43 \\
101,71\end{array}$ & $\begin{array}{l}32,63 \\
35,08 \\
37,76\end{array}$ & $\begin{array}{l}34,84 \\
37,33 \\
39,64\end{array}$ & $\begin{array}{l}19,11 \\
18,63 \\
19,10\end{array}$ & $\begin{array}{l}19,98 \\
20,86 \\
19,44\end{array}$ \\
\hline Média o & $\begin{array}{l}\text { preparo } \\
\text { C } \\
R \\
D\end{array}$ & & & & & $\begin{array}{l}29,56 \mathrm{~b} \\
31,95 \mathrm{~b} \\
36,22 \mathrm{a}\end{array}$ & & $\begin{array}{l}20,05 a \\
20,16 a \\
19,47 a\end{array}$ & \\
\hline Média c & $\begin{array}{l}\text { cultura } \\
/ M \\
/ M \\
+E / M+C\end{array}$ & & & & & $\begin{array}{l}30,44 \mathrm{~b} \\
32,96 \mathrm{a} \\
34,33 \mathrm{a}\end{array}$ & & $\begin{array}{l}20,17 a \\
20,00 a \\
19,51 \text { a }\end{array}$ & \\
\hline Média c & $\begin{array}{l}\text { dose N } \\
139 \\
139\end{array}$ & & & & & $\begin{array}{l}31,49 \mathrm{~b} \\
33,66 \mathrm{a}\end{array}$ & & $\begin{array}{l}19,38 \mathrm{~b} \\
20,40 \mathrm{a}\end{array}$ & \\
\hline Campo & ativo & & & & & 44,76 & & 22,45 & \\
\hline Inicial ( & 985)(1) & & & & & 32,55 & & 19,06 & \\
\hline
\end{tabular}

(1) Freitas (1988).

Médias seguidas de letras iguais, nas colunas, dentro de cada fator, não diferem entre si pelo teste de Tukey a $5 \%$. PC = Preparo convencional, PR = Preparo reduzido, PD = Plantio Direto, $\mathrm{A}=$ aveia, $\mathrm{M}=$ milho, $\mathrm{E}=$ ervilhaca, $\mathrm{C}=$ caupi, $\mathrm{NO}=$ zero $\mathrm{kg} \mathrm{ha}^{1} \mathrm{~N}$ mineral, e N139 $=139 \mathrm{~kg} \mathrm{ha}^{-1} \mathrm{~N}$ mineral.

condiçãoinicial em 1985. Observa-seque oPC A/M, mesmo com adição de N, apresentou redução deCOT em praticamente toda a camada de 0-0,175 m. Por sua vez, o PD A +E/M + C promoveu uma recuperação nos teores de COT desde a superfície do solo atéà profundidade de $0,075 \mathrm{~m}$, com redução na camada de 0,075-0,175 m. No entanto, a diferença nos estoques de COT do solo entre os sistemas PC A/M NO e PD A +E/M + C N139 foi de 13,77 $\mathrm{Mg} \mathrm{ha}^{-1}$ (F igura 4a).

A relação entre o $C$ adicionado $(A)$ e a variação anual nos estoques de COT no solo (dC/dt), cal culada em relação ao estoque inicial de COT na camada de $0-0,175 \mathrm{~m}\left(32,55 \mathrm{Mg} \mathrm{ha}^{-1}\right)$, encontra-se na figura $5 \mathrm{a}$. Verifica-se que os sistemas de culturas sob PC apresentaram taxas negativas (perdas) dealteração dos estoques de COT, variando de -0,51 a
$-0,05 \mathrm{Mg} \mathrm{ha}^{-1} \mathrm{ano}^{-1}$. Em PR, as taxas foram negativas ou muito baixas $\left(-0,26\right.$ a $\left.0,10 \mathrm{Mg} \mathrm{ha}^{-1} \mathrm{ano}^{-1}\right)$ e sempre positivas em PD $\left(+0,01\right.$ a $\left.+0,56 \mathrm{Mg} \mathrm{ha}^{-1} \mathrm{ano}^{-1}\right)$. A aplicação de $\mathrm{N}$ mineral reduziu as taxas negativas e aumentou as positivas (Figura $5 b$ ).

O tratamentoPC A/M NO apresentou a maior taxa de perda de C $\left(-0,51 \mathrm{Mg} \mathrm{ha}^{-1} \mathrm{ano}^{-1}\right)$ e oPD A +E/M + C N139 a maior taxa deacúmulo (0,56 $\left.\mathrm{Mg} \mathrm{ha}^{-1} \mathrm{ano}^{-1}\right)$ (Figura 5a). O acúmulo diferencial de COT no solo nestes sistemas extremos de manejo de solo $\left(1,06 \mathrm{Mg} \mathrm{ha}^{-1} \mathrm{ano}^{-1}\right)$ foi semelhante aos valores de 1,0 e 1,1 Mg ha-1 ano-1 verificados aos cinco (Bayer \& Mielnizuk, 1997) e noveanos (Bayer et al., 2000b) do presente experimento. Estes resultados evidenciam que o efeito líquido dos sistemas de manejo nos estoques de COT do sol otem apresentado magnitude semelhante ao longo do período 

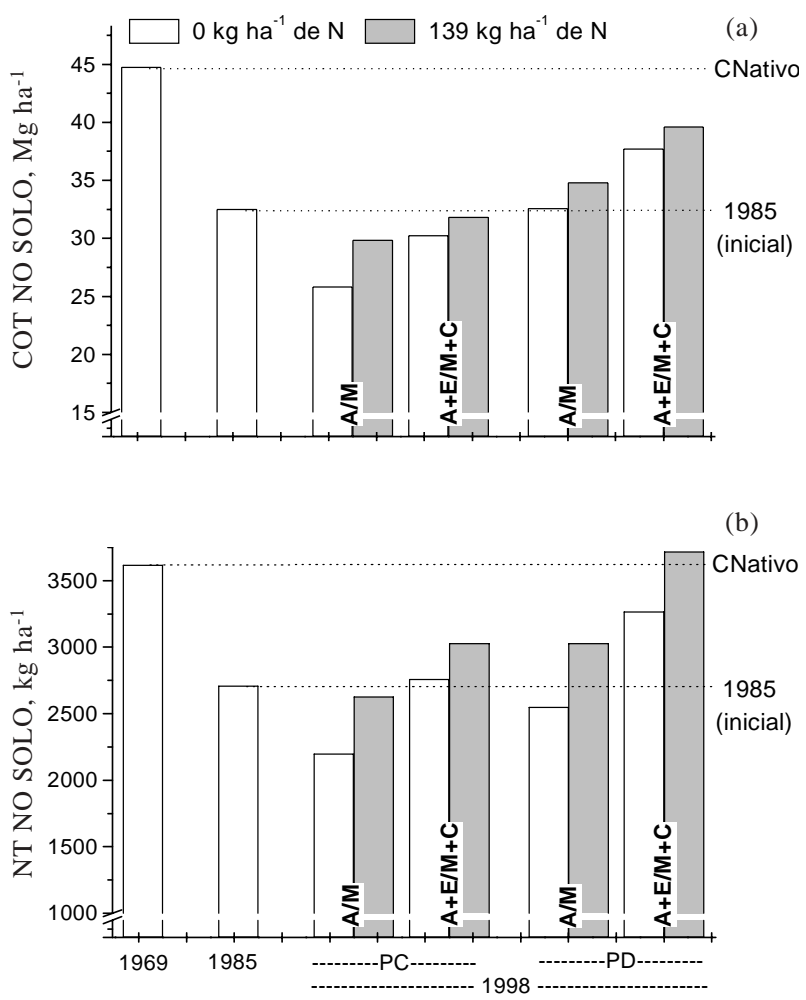

ANO E SISTEMA DE MANEJO DE SOLO

Figura 3. Estoques de carbono orgânico total-COT (a) e de nitrogênio total-NT (b) no solo (0-0,175 m) sob campo nativo (1969), referência da condição original do solo, por ocasião do início do experimento (1985), e após 13 anos (1998) da utilização dos sistemas de preparo convencional (PC) e plantio direto (PD) nos sistemas de culturas aveia/mi lho-A/M e aveia + ervilhaca/milho + caupi-A +E/M + C.

experimental, o que significa que, provavelmente, ao final dos 13 anos, ainda não tenham sido al cançados os respectivos estoques estáveis de COT no sol o nos diferentes sistemas de manejo.

Verificou-se que apenas o PD favoreceu 0 aumento do estoque de COT no solo, sendo a magnitude das taxas muito dependentes da quantidade de $\mathrm{C}$ adicionado pelos sistemas de culturas (Figura 5a). Dentre outros fatores, estes resultados explicam a variação das taxas deacúmulo do COT do sol o encontradas na literatura (Corazza et al., 1999; Lal et al., 1999; Amado et al., 2001; Freixo et al., 2002). Esse efeito da adição de C na taxa de acúmulo de COT no solo fica bastante evidente nos resultados relatados por Bayer et al. (2000a), segundo o qual a taxa de seqüestro de C no sol o em oito sistemas de culturas em plantio direto, calculada em relação a um sistema pousio/milho, variou de 0,13 a $0,97 \mathrm{Mg} \mathrm{ha}^{-1} \mathrm{ano}^{-1}$, estando diretamente relacionada com as adições anuais de C pelas culturas.

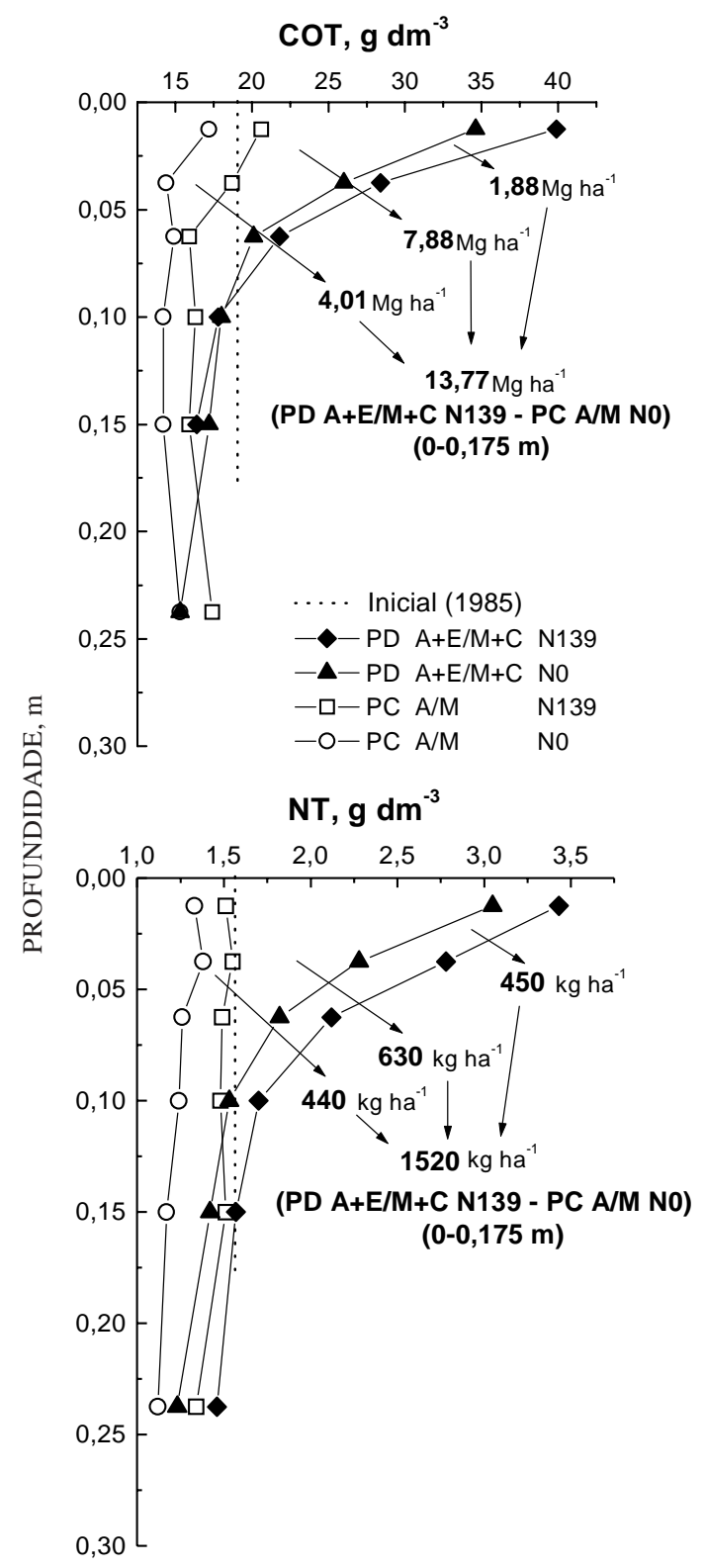

Figura 4. Distribuição dos teores de carbono orgânico total-COT (a) e de nitrogênio total-NT (b) no perfil do solo no início do experimento (1985) e 13 anos após, nos tratamentos com situações extremas de revolvimento do solo e de adição de $\mathbf{N}$. PC = preparo convencional, PD = plantio direto, $\mathbf{A}=$ aveia, $\mathbf{M}=$ milho, $\mathbf{E}=$ ervilhaca, $\mathbf{C}=$ caupi.

A extrapolação para períodos mais longos dos efeitos dos sistemas de culturas e dos preparos de solo poderá ser feita por meio do ajuste de modelos de simulação, como os utilizados por Bayer et al. (2000c) e Lovato (2001). No entanto, estes model os exigem o conhecimento prévio das taxas de conversão efetiva anual do $\mathrm{C}$ adicionado em COT (matéria orgânica) do solo $\left(\mathrm{k}_{1}\right)$ e da taxa de decomposição ou de perda anual do COT do solo $\left(k_{2}\right)$. 

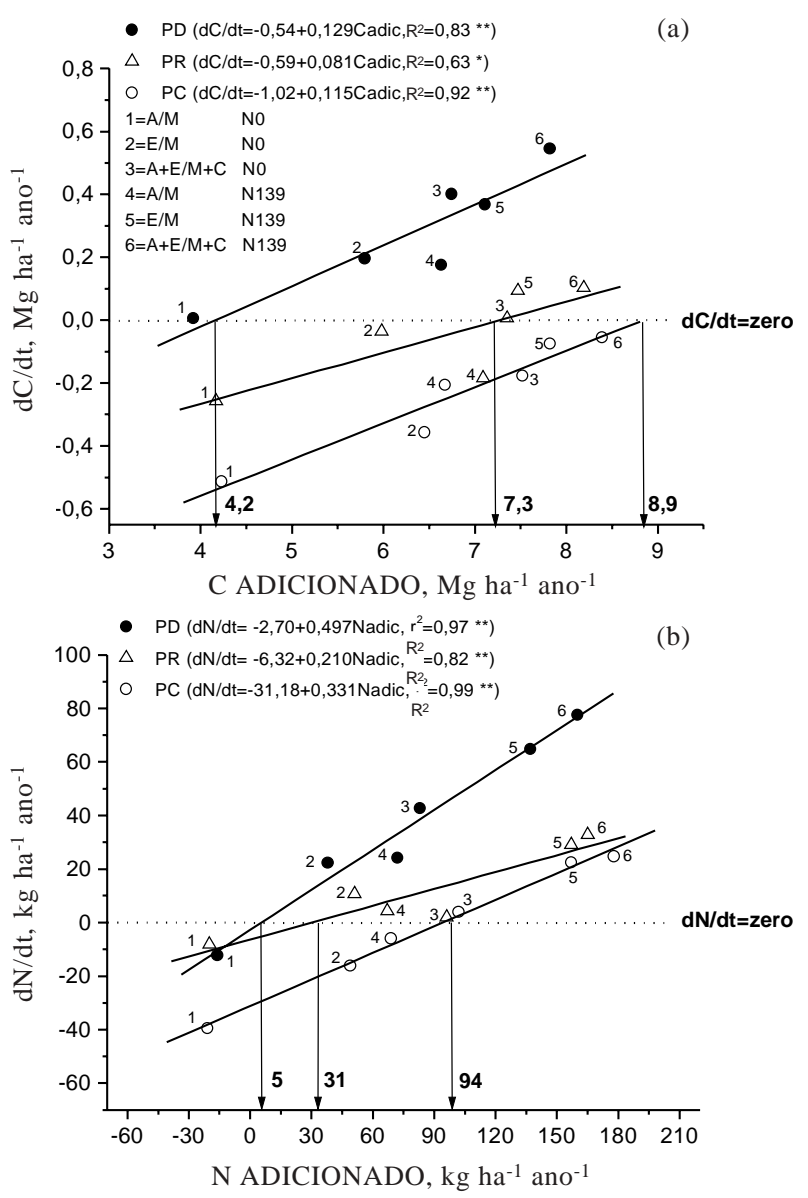

Figura 5. Relação entre as quantidades de car bono (a) e de nitrogênio (b) adicionadas com a variação (dC/dt, dN/t) dos estoques destes elementos na camada de 0-0,175 $\mathrm{m}$ do solo submetido aos sistemas de preparo convencional (PC), preparo reduzido (PR) e plantio direto (PD) e três sistemas de culturas, com e sem adição de $\mathbf{N}$ mineral. $\mathbf{A}=$ aveia, $\mathbf{M}=$ milho, $\mathbf{E}=$ ervilhaca, $\mathbf{C}=$ caupi. * $\mathbf{e}^{* *}$ : Significativo a 5 e $1 \%$, respectivamente.

A determinação do $k_{1}$ normalmenteé feita com base em resultados de técnicas isotópicas (Balesdent \& Balabane, 1996). Entretanto, valores aproximados de $k_{1}$ também podem ser obtidos com base em experimentos de longa duração, conhecendo-se as adições anuais de $C$ pelas culturas e a respectiva variação nos estoques de COT do solo em relação ao início do experimento.

$\mathrm{Na}$ figura $5 \mathrm{a}$, apresenta-se a relação entre a quantidade de $C$ adicionado (A) anualmente pelos sistemas de culturas e a taxa de variação anual (dC/dt) dos estoques deCOT na camada de 0-0,175 m em relação ao estoque inicial de COT em 1985 $\left(32,55 \mathrm{Mg} \mathrm{ha}^{-1}\right)$. O coeficiente angular das equações representa o $k_{1}$, ou seja, a fração (ou percentagem) do $C$ adicionado que efetivamente permanece no solo. Observa-se que ok ${ }_{1}$ foi maior no PD (0,129 ou $\left.12,9 \%\right)$ emenor no PR ( 0,081 ou 8,1 \%), sendo intermediário no PC $(0,115$ ou $11,5 \%)$. Estes val ores estão dentro da faixa de 7 a $23 \%$ relatada na literatura (Bolinder et al., 1999).

É possível que os valores de $\mathrm{k}_{1}$ obtidos por este procedimento sejam subestimados, e isto se deve ao fato de que a adição de $C$ pelas culturas compensam mai ores quantidades perdidas de COT anualmente $\left(\mathrm{k}_{2} \mathrm{C}\right)$ nos tratamentos que apresentam maiores estoques de COT no solo, determinando menor coeficiente angular da equação que relaciona a adi ção anual de C com a variação do COT no solo (dC/dt).

Conhecendo $\mathrm{k}_{1}$, pode-se obter o $\mathrm{k}_{2}$, partindo-se da equação $\mathrm{dC} / \mathrm{dt}=\mathrm{k}_{1} \mathrm{~A}-\mathrm{k}_{2} \mathrm{C}$, na condição de $\mathrm{dC} /$ dt =zero (Dalal \& Mayer, 1986; Bayer et al., 2000c; Lovato, 2001). Nesta condição, $k_{1} A=-k_{2} C$ e $\mathrm{k}_{2}=\mathrm{k}_{1} \mathrm{~A} / \mathrm{C}$, em que $\mathrm{A}$ é a taxa anual de adição de $C$ pel os sistemas de culturas e $C$ é o estoque de COT no solo. No caso representado na figura 5a, para manter o estoque de COT do sol o que havia no início do experimento (32,55 $\left.\mathrm{Mg} \mathrm{ha}^{-1}\right)$, ou seja, $\mathrm{dC} / \mathrm{dt}=$ zero, seria necessária uma adição anual deC pelas culturas de 4,2 $\mathrm{Mg}^{-1} \mathrm{ano}^{-1}$ no PD, 7,3 $\mathrm{Mg} \mathrm{ha}^{-1}$ ano $^{-1}$ no PR, e $8,9 \mathrm{Mg} \mathrm{ha}^{-1} \mathrm{ano}^{-1}$ no $\mathrm{PC}$, equivalendo a valores de $\mathrm{k}_{2}$ de $0,0166 \mathrm{ano}^{-1}(4,2 \times 0,129 \div 32,55), 0,0181 \mathrm{ano}^{-1}$ $(7,3 \times 0,081 \div 32,55)$ e 0,0314 ano $^{-1}(8,9 \times 0,115 \div$ $32,55)$, respectivamente. Os valores de $k_{2}$ estimados, embora coerentes, são mais baixos do que os obtidos por Bayer et al. (2000c) e Lovato (2001), o que possivel mente decorre do fato de que estes autores utilizaram um valor de $k_{1}$ fixo de 0,20 , o qual foi determinado por Cerri (1986) para a cultura da canade-açúcar em preparo convencional, num Latossolo da região de Piracicaba (SP).

Sepersistirem as atuais tendências representadas nas figuras $3 a$ e $5 a$, a recuperação dos estoques de COT no solo em campo nativo é impraticável nos sistemas de PC e PR. Com o sistema PD, este objetivo pode ser atingi do, desde que coma utilização deculturas com el evada adição de biomassa ao solo. Provavelmente, o uso de pastagens perenes, cuja adição de C diretamente ao solo pelo sistema radicular émais alta do que em culturas anuais, bem

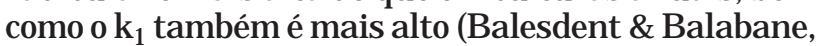
1996; Bolinder et al., 1999), viabilizaria também a recuperação do estoque de COT ao nível do solo em campo nativo.

\section{Alterações nos estoques de N total (NT) do solo}

O estoque original de NT da camada de $0-0,175$ m do sol o em campo nativo ( $3.620 \mathrm{~kg} \mathrm{ha}^{-1}$ ) foi reduzido pelo cultivo no período 1969-1984 para $2710 \mathrm{~kg} \mathrm{ha}^{-1}$. Durante o período experimental, os estoques de NT do solo nesta camada foram alterados significativamente pel os preparos de solo, sistemas de culturas e doses de N. À semelhança do COT, nãoforam observadas interações significativas entre os efeitos dos tratamentos nos estoques de NT do solo. Na camada de $0,175-0,30 \mathrm{~m}$, o estoque de NT 
do solo foi pouco influenciado pelo cultivo anterior ao experimento e, durante o período experimental, foi afetadosignificativamente pelos preparos de solo e doses de N (Figura 3b e Quadro 3).

$O$ estoque de NT foi maior no solo em PD, intermediário no solo em $P R$, e menor no solo em PC (Quadro 3). Os sistemas de culturas E/M eA +E/ $M+C$, pela presença de leguminosas, promoveram maior acúmulo de NT em relação ao sistema A/M. A aplicação de $\mathrm{N}$ mineral aumentou o estoque de NT nas camadas de 0-0,175 e 0,175-0,30 m, e, nesta última camada, o PR também promoveu aumento do NT em relação ao PC e PD.

$\mathrm{Na}$ figura 3b, estão representados os estoques de NT na camada de 0-0,175 m do solo nos tratamentos
A/M-PC e PD e A +E/M +C-PC e PD, com e sem aplicação de $\mathrm{N}$ mineral, esua relação com os estoques de NT inicial (1985) e original (campo nativo). Verifica-se, nesta figura, que o sistema com maior adição de $\mathrm{N}$ e sem revolvimento do solo (PD A +E/ $\mathrm{M}+\mathrm{C} \operatorname{com} \mathrm{N}$ ) recuperou e até superou o estoque de NT do solo em campo nativo. Esta recuperação, conforme pode ser visualizada na figura $4 \mathrm{~b}$, ocorreu principalmente nas camadas superficiais. Porém, observa-se uma nítida tendência do efeito das práticas de manejo no estoque de NT na camada de 0,175-0,30 m, evidenciado pela diferença de $430 \mathrm{~kg} \mathrm{ha}^{-1}$ entre os tratamentos extremos (PC A/M $\mathrm{NO}$ e PD A + E/M + C N139) nessa camada (Quadro 3). Resultados de deslocamento de N mineral e deacúmulo deNT em profundidadeforam

Quadro 3. Nitrogênio adicionado ao solo em base anual (média) e em 13 anos (total) por sistemas de cultura, em duas doses de N, e estoques de nitrogênio total (NT) nas camadas de 0-0,175 e 0,1750,30 m de um Argissolo Vermel ho sob campo nativo, por ocasião da instalação do experimento (1985) e após 13 anos (1998) sob três sistemas de preparo de solo, três sistemas de culturas e duas doses de N mineral

\begin{tabular}{|c|c|c|c|c|c|c|c|c|c|}
\hline \multirow{2}{*}{\multicolumn{2}{|c|}{ Sistema de manejo }} & \multicolumn{4}{|c|}{$\mathrm{N}$ adicionado } & \multicolumn{4}{|c|}{ NT (1998) } \\
\hline & & \multicolumn{2}{|c|}{ No } & \multicolumn{2}{|c|}{$\mathbf{N}_{139}$} & \multicolumn{2}{|c|}{$0-0,175 \mathrm{~m}$} & \multicolumn{2}{|c|}{$0,175-0,30 \mathrm{~m}$} \\
\hline Preparo & Cultura & Média & Total & Média & Total & $\mathbf{N}_{0}$ & $\mathbf{N}_{139}$ & $\mathbf{N}_{\mathbf{0}}$ & $\mathbf{N}_{139}$ \\
\hline & & & & & $-\mathrm{kgr}$ & ${ }^{-1}$ de N & 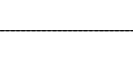 & - & 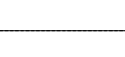 \\
\hline PC & $\begin{array}{l}A / M \\
E / M \\
A+E / M+C\end{array}$ & $\begin{array}{r}-21 \\
49 \\
102\end{array}$ & $\begin{array}{r}-273 \\
637 \\
1326\end{array}$ & $\begin{array}{r}69 \\
157 \\
178\end{array}$ & $\begin{array}{r}897 \\
2.041 \\
2.314\end{array}$ & $\begin{array}{l}2.200 \\
2.500 \\
2.760\end{array}$ & $\begin{array}{l}2.630 \\
3.000 \\
3.030\end{array}$ & $\begin{array}{l}1.390 \\
1.640 \\
1.660\end{array}$ & $\begin{array}{l}1.680 \\
1.800 \\
1.690\end{array}$ \\
\hline PR & $\begin{array}{l}A / M \\
E / M \\
A+E / M+C\end{array}$ & $\begin{array}{r}-20 \\
51 \\
96\end{array}$ & $\begin{array}{r}-260 \\
663 \\
1248\end{array}$ & $\begin{array}{r}67 \\
157 \\
165\end{array}$ & $\begin{array}{r}871 \\
2.041 \\
2.145\end{array}$ & $\begin{array}{l}2.600 \\
2.850 \\
2.740\end{array}$ & $\begin{array}{l}2.770 \\
3.090 \\
3.140\end{array}$ & $\begin{array}{l}1.790 \\
1.820 \\
1.640\end{array}$ & $\begin{array}{l}1.760 \\
1.680 \\
1.840\end{array}$ \\
\hline PD & $\begin{array}{l}A / M \\
E / M \\
A+E / M+C\end{array}$ & $\begin{array}{r}-16 \\
38 \\
83\end{array}$ & $\begin{array}{r}-208 \\
494 \\
1079\end{array}$ & $\begin{array}{r}72 \\
137 \\
160\end{array}$ & $\begin{array}{r}936 \\
1.781 \\
2.080\end{array}$ & $\begin{array}{l}2.550 \\
3.000 \\
3.270\end{array}$ & $\begin{array}{l}3.030 \\
3.550 \\
3.720\end{array}$ & $\begin{array}{l}1.520 \\
1.580 \\
1.530\end{array}$ & $\begin{array}{l}1.610 \\
1.630 \\
1.820\end{array}$ \\
\hline \multicolumn{10}{|c|}{ Média de preparo } \\
\hline & $\begin{array}{l}\mathrm{C} \\
\mathrm{R} \\
\mathrm{D}\end{array}$ & & & & & $\begin{array}{l}2.690 \mathrm{~b} \\
2.860 \mathrm{ab} \\
3.130 \mathrm{a}\end{array}$ & & $\begin{array}{l}1.650 \mathrm{~b} \\
1.770 \mathrm{a} \\
1.620 \mathrm{~b}\end{array}$ & \\
\hline \multicolumn{10}{|c|}{ Média de cultura } \\
\hline & $\begin{array}{l}/ M \\
: M \\
+E / M+C\end{array}$ & & & & & $\begin{array}{l}2.630 \mathrm{~b} \\
2.940 \mathrm{a} \\
3.110 \mathrm{a}\end{array}$ & & $\begin{array}{l}1.680 a \\
1.700 a \\
1.700 a\end{array}$ & \\
\hline \multicolumn{10}{|c|}{ Média de dose $\mathrm{N}$} \\
\hline \multicolumn{2}{|c|}{$\begin{array}{l}\mathrm{N}_{0} \\
\mathrm{~N}_{139}\end{array}$} & & & & & $\begin{array}{l}2.720 \mathrm{~b} \\
3.070 \mathrm{a}\end{array}$ & & $\begin{array}{l}1.630 \mathrm{~b} \\
1.720 \mathrm{a}\end{array}$ & \\
\hline \multicolumn{2}{|c|}{ Campo nativo } & & & & & 3.620 & & 1.700 & \\
\hline \multicolumn{2}{|c|}{ Inicial (1985)(1) } & & & & & 2.710 & & 1.630 & \\
\hline
\end{tabular}

Médias seguidas de letras iguais, nas colunas, dentro de cada fator, não diferem entre si pelo teste de Tukey a $5 \%$. $\mathrm{PC}=$ Preparo convencional, $\mathrm{PR}=$ Preparo reduzido, $\mathrm{PD}=$ Plantio Direto, $\mathrm{A}=$ aveia, $\mathrm{M}=$ milho, $\mathrm{E}=$ ervilhaca, $\mathrm{C}=$ caupi, $\mathrm{NO}=$ zero $\mathrm{kg} \mathrm{ha}^{-1} \mathrm{~N}$ mineral, e N139 $=139 \mathrm{~kg} \mathrm{ha}^{-1} \mathrm{~N}$ mineral. ${ }^{(1)}$ Freitas (1988). 
obtidos por Diekow et al. (2002), em experimento com 17 anos de duração neste mesmo solo, em tratamentos com al ta adição de $\mathrm{N}$ anual mente pelas culturas de guandu (Cajanus cajan) e lab-lab (Dolichos lablab). Este fenômeno pode ser positivo pelo aumento de $\mathrm{N}$ em camadas mais profundas do solo. Por outrolado, o N mineral, se atingir olençol freático pode ocasionar danos ambientais.

A relação entreo $\mathrm{N}$ adicionado ea variação anual (dN/dt) nos estoques de NT do solo, relativa ao estoque inicial de NT na camada de 0-0,175 m $\left(2,64 \mathrm{Mg} \mathrm{ha}^{-1}\right)$, encontra-sena figura $5 \mathrm{~b}$. Observamseal tos coeficientes de determinação $\left(R^{2}\right)$ entre estas variáveis, indicando que as estimativas do $\mathrm{N}$ adicionado são coerentes, visto que a quantificação do estoque de NT do solo é relativamente precisa. Verifica-se que, sem a aplicação de $\mathrm{N}$ mineral, as taxas foram positivas, ou seja, ocorreram acúmulos de NT no solo, apenas nos tratamentos PC A +E/ $\mathrm{M}+\mathrm{C}, \mathrm{PR} \mathrm{E} / \mathrm{M}, \mathrm{PR} \mathrm{A}+\mathrm{E} / \mathrm{M}+\mathrm{C}, \mathrm{PD} \mathrm{E} / \mathrm{M}$ ePD A + E/ $\mathrm{M}+\mathrm{C}$ (Figura $5 \mathrm{~b}$ ). Com a aplicação de $\mathrm{N}$ mineral, as taxas foram positivas em todos os tratamentos, com exceção ao PC A/M, indicando que parte do N aplicado como adubo foi retido na matéria orgânica do solo.

Da mesma forma como para o COT, os coeficientes angulares das equações representam quanto do $\mathrm{N}$ adicionado foi efetivamente convertido em NT no solo. Os resultados demonstram que aproximadamente $50 \%$ do $\mathrm{N}$ adicionado foi retido como NT no solo em PD, em comparação com a retenção de $21 \%$ no solo em PR e de $33 \%$ no solo emPC. Conforme discutido para oCOT (Figura 5a), a adição anual de $\mathrm{N}$ necessária para manter o NT no sol o no nível do início do experimento é de 5, 31 e $94 \mathrm{~kg} \mathrm{ha}^{-1} \mathrm{ano}^{-1}$ no PD, PR e PC, respectivamente. $\mathrm{O}$ menor valor de retenção do $\mathrm{N}$ adicionado no solo em PR revela a necessidade de pesquisa em relação à intensidade dos processos de perdas de $\mathrm{N}$ no solo escarificado.

Pelos resultados obtidos ao final de 13 anos do experimento (Figura $5 b$ ), a recuperação dos estoques de NT no solo em campo nativo é inviável com o uso de PR e PC. Por outrolado, o estoque de NT do solo pode ser recuperado no sistema PD, salientando-se, entretanto, a importância das espécies leguminosas com alta produção de resíduos vegetais nos sistemas de culturas, e da adubação nitrogenada, que contribui para a manutenção dos estoques de NT e de COT do solo, para a qualidade do solo e do ambiente e para a produtividade do milho.

\section{CONCLUSÕES}

1. A inclusão de leguminosas em sistemas de culturas e a adubação nitrogenada contribuíram para a maior adição anual de $\mathrm{C}$ e de $\mathrm{N}$ ao solo, a qual foi diretamente relacionada com as alterações dos estoques destes el ementos no solo e com a produtividade do milho.

2. A recuperação dos estoques de $C$ orgânico e de $\mathrm{N}$ total ocorreu apenas no solo em plantio direto, o que indica que a eliminação do revol vimento do solo é uma prática fundamental, quando se tem por objetivo a recuperação de sol os degradados na região subtropical do Sul do Brasil.

3. A partir da relação entre a adição de $C$ pelas culturas e a variação nos estoques deste elemento no solo, ambos em base anual, foram estimados valores aproximados do coeficiente de humificação $\left(\mathrm{k}_{1}\right)$ e da taxa anual de perda de matéria orgânica $\left(k_{2}\right)$ no solo; os maiores valores de $k_{1}$ e os menores de $k_{2}$ ocorreram no solo em PD, o que explica o maior acúmulo de COT no sol o, em comparação aos demais sistemas de preparo de solo. O N apresentou comportamentosimilar ao do C orgânico no solo, com maior retenção e menores perdas no solo em plantio direto.

\section{LITE RATURA CITADA}

ADDISCOTT, T.M. Entropy and sustainability. Eur. J . Soil Sci., 46:161-168, 1995.

BAYER, C.; MARTIN-NETO, L.; MIELNICZUK, J \& \& CERETTA, C.A. Effect of no-till cropping systems on soil organic matter in a sandy clay loam Acrisol from southern Brazil monitored by electron spin resonance and nuclear magnetic resonance. Soil Till. Res., 53:95-104, 2000a.

BAYER, C.; MIELNICZUK, J . \& MARTIN-NETO, L. Efeito de sistemas de preparo e de cultura na dinâmica da matéria orgânica e na mitigação das emissões de $\mathrm{CO}_{2}$. R. Bras. Ci. Solo, 24:599-607, 2000c.

BAYER, C.; MIELNICZUK,J .; AMADO, T.J .C.; MARTIN-NETO, L. \& FERNANDES, S.V. Organic matter storagein a sandy clay loam Acrisol affected by tillage and cropping systems in southern Brazil. Soil Till. Res., 54:101-109, 2000b.

BERGAMASCHI, H.\& GUADAGNIN, M.R. Agroclima da Estação Experimental Agronômica. Porto Alegre, Universidade Federal do Rio Grande do Sul, 1990. 96p.

BOLINDER, M.A.; ANGERS, D.A.; GIROUX, M. \& LAVERDIÈRE, M.R. Estimating $C$ inputs retained as soil organic matter from corn (Zea mays L.). Plant Soil, 215:8591, 1999.

CERRI, C.C. Dinâmica da matéria orgânica do solo no agrossistema cana-de-açúcar. Piracicaba, Universidade de São Paulo, 1986. 197p. (Tese de Livre Docência)

CORAZZA, E.J .; SILVA, J .E.; RESK, D.V.S. \& GOMES, A.C. Comportamento de diferentes sistemas de manejo como fonte ou depósito de carbono em relação à vegetação de cerrado. R. Bras. Ci. Solo, 23:425-432, 1999.

DALAL, R.C. \& MAYER, R.J . Long-term trends in fertility of soils under continuous cultivation and cereal cropping in southern Queensland. I. Total organic carbon and its rate of loss from the soil profile. Aust. J . Soil Res., 24:281-292, 1986. 
DIEKOW, J .; MIELNICZUK, J .; VEZZANI, F.M. \& LOVATO, T. Nitrogênio inorgânico do solo em sistemas de cultura de milho e leguminosas estivais sob plantio direto. In: REUNIÃO BRASILEIRA DE FERTILIDADE DO SOLO, 25., Rio deJ aneiro, 2002. Anais. Rio deJ aneiro, 2002. CDROM

EMPRESA BRASILEIRA DE PESQUISA AGROPECUÁRIA EMBRAPA. Centro Nacional de Pesquisa de Solos. Sistema Brasileiro de Classificação de Solos. Brasília, 1999. 412p. il. (EMBRAPA/CNPS-RJ . Documento, 5)

FELLER, C. \& BEARE, M.H. Physical control of soil organic matter dynamics in thetropics. Geoderma, 79:69-117, 1997.

FREITAS, V.H. Eficiência de sistemas de preparo do solo e de culturas no fornecimento de nitrogênio para o milho. Porto Alegre, Universidade F ederal do Rio Grande do Sul, 1988. 148p. (Tese de Mestrado)

FREITAS, V.H.; ROSSO, A.; MIELNICZUK, J . \& BAYER, C. Efeito de métodos de preparo do solo e sistemas de cultura na absorção de nitrogênio e rendimento do milho. Pesq. Agropec. Gaúcha, 2:69-77, 1996.

FREIXO, A.F.; MACHADO, P.L.O.A.; SANTOS, H.P.; SILVA, C.A. \& FADIGAS, F.S. Soil organic and fractions of Rhodic Ferralsol under the influence of tillage and crop rotation systems in southern Brazil. Soil Till. Res., 64:221-230, 2002.

LAL, R.; FOLLET, R.F.; KIMBLE, J . \& COLE, C.V. Managing U.S. cropland to sequester carbon in soil. J. Soil Water Conserv., 5:374-381, 1999.

LOVATO, T. Dinâmica do carbono e do nitrogênio do sol o afetada por preparos do solo, sistemas de cultura e adubo nitrogenado. Porto Alegre, Universidade Federal do Rio Grande do Sul, 2001. 130p. (Tese de Doutorado)

MILLER, R.M. \& JASTROW, J.D. Hierarchy of root and mycorrhizal fungal interactions with soil aggregation. Soil Biol. Biochem., 22:579-584, 1990.
RAMOS, M.G.; VILLATORO, M.A.A.; URQUIAGA, S.; ALVES, B.J .R. \& BODDEY, R.M. Quantification of the contribution of biological nitrogen fixation to tropical green manurecrops and the residual benefit to a subsequent maize crop using 15N-isotopic techniques. J . Biotechnol., 91:105-115, 2001.

SHAMOOT, S.; MacDONALDS, L. \& BARTHOLOMEW, W.V. Rhizodeposition of organic matter debris in soil. Soil Sci. Soc. Am. J ., 32:817-820, 1968.

SILVA, I.F. \& MIELNICZUK, J. Ação do sistema radicular de plantas na formação e estabilização de agregados de solo. R. Bras. Ci. Solo, 21:113-117, 1997.

SIX, J .; ELLIOTT, E.T. \& PAUSTIAN, K. Aggregate and soil organic matter dynamics under conventional and no-tillage systems. Soil Sci. Soc. Am. J ., 63:1350-1358, 1999.

SOIL SURVEY STAFF. Keys to soil taxonomy. 8 ed. Washington, 1998. 326 p.

TEDESCO, M.J .; GIANELLO, C.; BISSANI, C.A.; BOHNEN, H. \& VOLKWEISS, S.J. Análise de solo, plantas e outros materiais. 2 ed. Porto Alegre, Universidade Federal do Rio Grande do Sul, 1995. 174p.

TEIXEIRA, L.A.J .; TESTA, V.M. \& MIELNICZUK, J . Nitrogênio do solo, nutrição e rendimento de milho afetados por sistemas de cultura. R. Bras. Ci. Solo, 18:207-214, 1994.

TESTA, V.M.; TEIXEIRA, L.A.J. \& MIELNICZUK, J. Características químicas de um Podzól ico Vermel ho-Escuro afetadas por sistemas de cultura. R. Bras. Ci. Solo, 16:107114, 1992.

TISDALL, J .M. \& OADES, J .M. Organic matter and waterstable aggregates in soils. J. Soil Sci., 33:141-163, 1982.

van BREEMER, N. Soils as biotic cronstruct favouring net primary productivity. Geoderma, 57:183-211, 1993.

VEZZANI, F.M. Qualidade do sistema sol o na produção agrícola. Porto Alegre, Universidade Federal do Rio Grande do Sul, 2001. 184p. (Tese de Doutorado) 